\title{
The Impact of Internal Control through Computerized Accounting System among Small and Medium Enterprises in Oman
}

Asila Mohamed alzakwani ${ }^{1}$, Maria Teresa Matriano ${ }^{2}$

Middle East College, Oman

Email: ${ }^{1} 15$ s13657@mec.edu.om, ${ }^{2}$ maria@mec.edu.om

Citation: Alzakwani, A. M. \& Matriano, M. T. (2021). The Impact of Internal Control through Computerized Accounting System among Small and Medium Enterprises in Oman. International Journal of Research in Entrepreneurship \& Business Studies, 2(3), $57-46$.

https://doi.org/10.47259/ijrebs.237

Received on $25^{\text {th }}$ Apr. 2021

Revised on $29^{\text {th }}$ May. 2021

Published on $6^{\text {th }}$ Jul. 2021

Copyright: (C) 2021 by the authors. Licensee Global Scientific Publications, Oman.

\section{Publishers Note:}

This work is licensed under a Creative Commons Attribution-ShareAlike 4.0 International License. This is an openaccess journal and the articles published in this journal are distributed under the terms of CC-BY-SA.

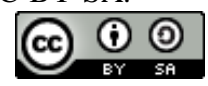

\begin{abstract}
Purpose: The aims of the study were to identify and evaluate the internal controls used in a computerized accounting system of the SMEs, to identify and evaluate the merits and demerits of the internal controls used in the companies, and to identify the challenges in the implementation of internal control systems in the computerized accounting system of the SMEs.

Design/methodology/approach: The population of the study was the employees of the SMEs registered with the Ministry of Commerce and Industry (MOCI) in Muscat, Oman. Samples were selected from this population on a random sampling basis. One member employee of the SMEs representing the enterprise filled the questionnaire. The survey was conducted through a questionnaire using a Google form. 220 samples were collected from the population. The data collected was analyzed using data processing methods and Microsoft excel.

Findings: The study found that SMEs were using computers to perform their daily transactions and the accounting software used by SMEs was cheap, of low quality, and not proficient enough. One of the components of the internal control system, i.e. monitoring was implemented by most of the SMEs and they also stated that they rarely hired an external auditor for auditing because of the expensive auditing fees. It was also stated that the security mechanisms were not properly implemented in the SMEs because of the expensive cost.

Research limitations/implications: The study suggested that the Government should emphasize the SMEs implement a good internal control system. This can reduce errors and also increase the efficiency of operations. SOX in the Omani context should be strictly implemented making it statutory and mandatory for all the SMEs in Oman and such statutory laws will help the auditors to abide by the rules and regulations to be followed.
\end{abstract}

Social Implications: Government should support SMEs by providing education on the importance of internal control systems as most of the employees of SMEs are poorly educated/illiterates. The Government should set a price ceiling to the external auditors on the auditing fees exclusively for SMEs so that they can afford them.

Originality / Value: No study was carried before in relates to the impact of the internal control system through the computerized accounting system among the SMEs in Muscat, Oman. This study will through light on the statutory laws required for the sake of internal control measures required for the SMEs.

Keywords: Internal control systems, Computerized accounting systems, SOX, Internal control, Small and Medium Enterprises, Main components of Internal Control System.

\section{Introduction}

Internal control is a system that controls financial transactions, enable securing the assets and accuracy (Adesoji, 2004). Internal control is defined as a tool to produce reliable financial reporting. Internal control is very important in any company to have a successful business. They are procedures that have been implemented to avoid a business failure. Internal control is a broad topic that includes the components, types, advantages, and even disadvantages of implementing it (Steinberg, 2013). 
Internal control helps in managing the risks and increases the protection of the asset within the organization. It helps the auditors to identify the areas which need more attention. The preventive control will help in identifying the areas in which fraud or theft may occur. It also helps the employees to follow the management policies and rules. In large organizations usually, the hierarchy process of approval is followed to reduce time wastage and the occurrence of fraud (Buabeng, 2020). But this does not apply to Small and Medium Enterprises (SMEs). This is usually done with documentation and has been communicated to all employees within the organization for their information and changes that take place.

Based on the theory of internal control development, internal control was characterized by the Committee of Sponsoring Organizations (COSO) with five components namely control environment, control activities, risk assessment, information and communication, and monitoring (Curtis \& Wu, 2000). COSO model and implementation of the Sarbanes-Oxley Act (SOX) can be a good tool when dealt with as an internal control (Kazaz et.al 2019).

\section{Internal Control Components}

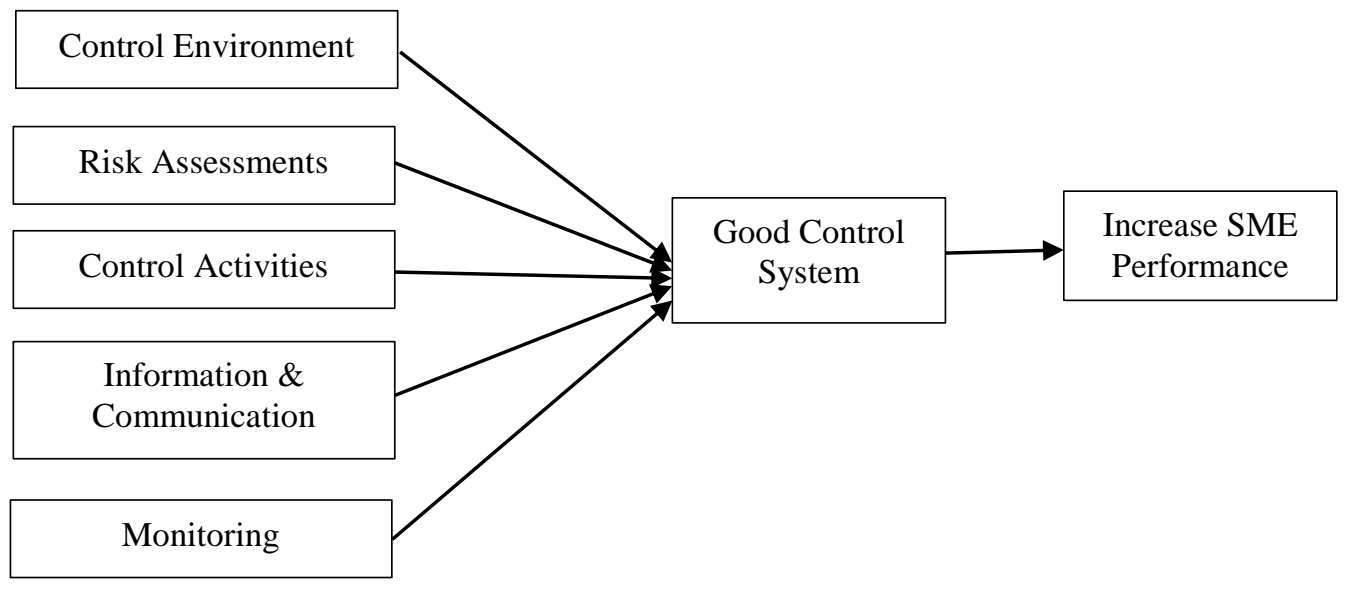

Figure 1 Good Internal Control System with Components

(Source: Curtis \& Wu, 2000; Shanmugam et al., 2012)

Figure 1 shows that the five components to be considered for a good internal control system. Each component has its function which contributes to better internal control. A good internal control system will increase the performance of SMEs by increasing their profit and reducing fraud activities. The security mechanism protects the company from data breaches or fraud which might happen within the company.

An effective internal control system needs the management to understand clearly the company objective and their environment. They also need to be aware of the limitations and the perfect measures to eliminate or reduce these limitations.

Computers have brought advantages to our lives but should be properly secured to avoid any unauthorized access and effective operation (Wei, 2015). According to the growth of technology, companies need to adapt the controls according to the technological changes. This has led the management to change the internal controls and that is where the internal audit takes the role. Internal control protects the companies from different risks such as theft, fraud, etc. Further, SMEs face a challenge such as fewer employees having no separation of duties/division of labor, which leads to knowingly and unknowingly human error commitment.

In the case of a poor internal control system, employees' performance declines to cause them to become frustrated. The poor decision made by the management under pressure due to limited time and the information available. These decisions can be found later to result in the less desirable results(Owusu-Ansah, 2019). 


\section{Problem Statement}

A company should have good internal control of its financial activities to avoid any fraud or theft. SMEs could not afford to have a good internal control system as it is expensive. An accountant is unable to check all the transactions carried out by the enterprise he/she belongs whereas a good internal control system will help to carry out the duties in an orderly manner and with ease. Further, SMEs are not carrying out internal audits frequently to ensure that the financial reports are reviewed and accurate. There seems to be no segregation of duties because of a smaller number of employees within the companies. In most companies, it is observed that the same employee receives cash and records the proceeds of the transactions as well. The quality of work may not be good as there is no segregation of duties concerning a specific task and there is no control over the transaction/assets. This might lead to theft and fraud (Khan, 2008; Putra, 2014). This has triggered the reason for the deep study of the internal control of the companies, SMEs in particular.

\section{Research Questions}

The following research questions came up during the study:

1. What was the internal control used in the computerized accounting system of the SMEs?

2. What were the merits and demerits of the internal control system used in the SMEs?

3. What were the challenges in the implementation of internal control in computerized accounting systems of the SMEs?

\section{Research Objectives}

The following objectives were defined in line with the above research questions:

1. To identify and evaluate the internal control used in the computerized accounting system of SMEs.

2. To analyze the merits and demerits of the internal control system used in SMEs.

3. To analyze the challenges in the implementation of internal control in the computerized accounting system of the companies.

\section{Review of Literature}

Internal control helps in keeping the record of the costs which occur and enables to make proper decisions (Frazer, 2016). Internal Control had a direct effect on the timely preparation of financial reports according to the principles with transparency (Mardi et al., 2020). Internal control system (ICS) eliminates the fraud and theft-related activities in a company as the work done by one employee is checked by the other (Dawson, 2015). The tangible and intangible assets of the company will be protected if there will be a good internal control system example reviewing the documents or recording the transactions (Buabeng, 2020).

The primary challenges of SMEs poor financial decision-making due to poor quality financial information and ineffective controls, which can be avoided through the introduction of computerized accounting systems (Abdulle et al., 2019; Yen-ling, 2017). For small and growing enterprises, the introduction of computerized financial accounting not only provides effective internal control but also ensures smooth financial accounting. (Zhang, 2021). Effective internal control systems are characterized by the integration of safety of the organizational systems and the reliability on them towards taking decisions (Lutui and 'Ahokovi, 2018). The risks of internal control systems can be eliminated through the introduction of an e-accounting system to improve the financial performance of the companies. (Soudani, 2013). Initiation of the anti-fraud program Sarbanes-Oxley Act (SOX) can be another alternative to have an effective internal control system (Dawson, 2015).

Internal control systems should be effective so that the employees to work without fear as there might be possibilities that some of the employees can override these controls (Akhmetshin et.al, 2018). Internal control plays a major role in employee performance and the accounting information system mediates between the two (Alawaqleh, 2021). Employees should follow all the corporate compliances which are mandatory by the organization (Owusu-Ansah, 2019). Awareness of the importance of the internal controls and applying the same with responsibility will enable the committed employees to benefit from such controls (Hanini, 2015). Human error might occur in internal control due to misunderstanding, error in judgment, carelessness of employees, or even tiredness of employees (Frazer, 2016). The overrides can be misused for reasons like increase sales target, increasing market values, hiding lack of compliance to the legalities, creating fake documents - duplicate invoices purchase orders, etc. Restricted access to assets and the devices and periodic physical control might be a solution to increase the security and protect the assets of the company (Loan, 2011). 
Internal Control Systems Components

An organizational strategy must include the implementation of the components of internal control systems to have effective internal control and gain a competitive advantage (Mahadeen et al., 2016). Committee of Sponsoring Organizations (COSO) characterized internal control with five components viz. Control Environment, Control Activities, Risk Assessment, Information and Communication, and Monitoring (Curtis and Wu, 2000). COSO's integrated framework for internal control is an effective internal control system (Fourie and Ackermann, 2013).

Control Environment ensures accountability, authority, and responsibilities of the employees and increases growth (Steinberg, 2013). Control Activities involve the accomplishment of company goals and overcome the risk if any arises and obstructs during the accomplishment of such goals (Elahi, 2013). The top management should communicate to employees the roles and responsibilities in terms of internal control and the importance of such Control Activities (Geiger et.al, 2014). Risk Assessment is the identification of the probability of an undesirable event that might arise the risk management is essential to avert or mitigate such risk from occurring (Dionne, 2013). Information and Communication of the same involve the process of passing on the information simply so that the information is properly conveyed promptly (Adewale, 2014; Lunenburg, 2010). Monitoring is continuously done to ensure the efficiency of controls and help the management to take proper decisions in case of negative progress (Sera and Beaudry, 2007).

\section{Research Methodology}

Descriptive research design aims at describing the population or situation or phenomenon in a systematic way (McCombes, 2020). when the research requires more details of a certain topic explanatory research is adopted (Kowalczyk, 2019). Therefore, a descriptive research pattern is used in this study.

The population of the study was the employees of the SMEs registered with the Ministry of Commerce and Industry (MOCI) in Muscat, Oman. Samples were selected from this population on a random sampling basis. One member employee from each SME representing the enterprise filled the questionnaire. The survey was conducted through a questionnaire using a Google Form. 220 samples were collected from the population. The data collected was analyzed using data processing methods and Microsoft excel.

\section{Findings}

Table 1 Gender

\begin{tabular}{|l|c|c|}
\hline Gender & Frequency & $\boldsymbol{\%}$ \\
\hline Male & 150 & 68.2 \\
\hline Female & 70 & 31.8 \\
\hline
\end{tabular}

Table 1 shows that the majority of the respondents (68.2\%) were males and females were only $31.8 \%$. It indicates that more male employees working in SMEs companies than females. Therefore, it could be concluded that more males were employed in Oman than women especially in SMEs. This result is similar to the findings of Alqassabi (2020) that the number of males who started businesses in Oman was more compared to females due to the culture and tradition which restrict women to startup businesses.

Table 2 Age

\begin{tabular}{|l|c|c|}
\hline \multicolumn{1}{|c|}{ Age } & Frequency & \% \\
\hline $20-30$ & 70 & 31.8 \\
\hline $30-40$ & 80 & 36.4 \\
\hline $40-50$ & 50 & 22.7 \\
\hline above 50 & 20 & 9.1 \\
\hline
\end{tabular}

Table 2 shows that the majority of the respondents (36.4\%) were of age between 30 and 40 . The next highest range was between 20 and 30 with $31.8 \%$ followed by the range of $40-50$ were $22.7 \%$. The least range was 
more than 50 years of age with $9.1 \%$. This indicated that the employees working in SMEs were young between $20-40$.

Table 3 Nationality

\begin{tabular}{|l|c|c|}
\hline Nationality & Frequency & $\boldsymbol{\%}$ \\
\hline Omani & 150 & 68.2 \\
\hline Non-Omani & 70 & 31.8 \\
\hline
\end{tabular}

Table 3 indicated that the majority $(68.2 \%)$ of the employees working in SMEs were Omanis whereas nonOmanis was only $31.8 \%$. This can be due to the Omanisation policy of the country (Curtis, 2015).

Table 4 Education Level

\begin{tabular}{|l|c|c|}
\hline \multicolumn{1}{|c|}{ Education Level } & Frequency & \% \\
\hline High School Graduate or less & 100 & 45.5 \\
\hline Diploma in Higher Education & 40 & 18.2 \\
\hline Bachelor Degree & 70 & 31.8 \\
\hline Masters & 10 & 4.5 \\
\hline
\end{tabular}

Table 4 indicates that the majority of the respondents (45.5\%) were high school graduates or less. Only a few of the respondents $(4.5 \%)$ were holding a Master's degree. The second-highest percentage of education level was with bachelor degree qualification with $31.8 \%$. This confirmed that the level of education of the people working in SMEs was of high school graduates or less. This result is similar to the findings of Alqassabi (2020) who stated that those people who could not complete their studies usually take the risk of starting a business to survive.

Table 5 Main component of Internal Control System Company focuses

\begin{tabular}{|l|c|c|}
\hline \multicolumn{1}{|c|}{$\begin{array}{c}\text { Internal Control System main } \\
\text { Component }\end{array}$} & Frequency & \% \\
\hline Control Environment & 15 & 6.8 \\
\hline Risk Management & 10 & 4.5 \\
\hline Control Activities & 80 & 36.4 \\
\hline Information and Communication & 40 & 18.2 \\
\hline Monitoring & 75 & 34.1 \\
\hline
\end{tabular}

Table 5 shows that the majority of the respondents $(36.4 \%)$ reported that they were using the Control activities to increase the effectiveness of internal control, followed by Monitoring as the second highest $(34.1 \%)$ measure to increase the internal control effectiveness. Risk Management was the least number of respondents reported with $4.5 \%$. This is similar to the finding by Gebramicheal and Habtegiorgis (2019) that the managers of SMEs mainly use the monitoring of transactions and controlling activities daily. Risk management is not their main concern as risk management is usually informal and less structured compare to large companies. 
Table 6 Implementation of Internal Control System Measures

\begin{tabular}{|l|c|c|}
\hline Implementation through & Frequency & $\mathbf{\%}$ \\
\hline Approval Process & 50 & 22.7 \\
\hline Segregation of Duties & 20 & 9.1 \\
\hline SOX Procedures & 0 & 0 \\
\hline Monitoring & 150 & 68.2 \\
\hline
\end{tabular}

Table 6 shows that the majority of the respondents $(68.2 \%)$ implement their internal control system through Monitoring, followed by the Approval Process with 22.7\%. None of the respondents opted for SOX as it is still not implemented in Oman. According to Greene (2017), SOX is not implemented in Oman and used mainly in the USA.

\section{Table 7 External Audit}

\begin{tabular}{|c|c|c|}
\hline Duration & Frequency & $\%$ \\
\hline Once a year & 54 & 24.5 \\
\hline Twice a year & 20 & 9.1 \\
\hline Frequently & 5 & 2.3 \\
\hline Rarely & 65 & 29.5 \\
\hline Never & 76 & 34.6 \\
\hline
\end{tabular}

Table 7 shows that the majority of the respondents (34.6\%) reported that they never hired an external auditor to audit their company. This might be because of the cost they have to pay to the auditor. However, $29.5 \%$ of the respondents reported that they rarely hired external auditors and $24.5 \%$ of the respondents reported that they hired external auditors once a year. Only $2.3 \%$ of the respondents reported that they frequently The cost of hiring an external auditor was reported to be high in Oman and the SMEs felt hard to afford.

Table 8 Main Issues/Challenges Faced

\begin{tabular}{|l|c|c|}
\hline \multicolumn{1}{|c|}{ Challenges } & Frequency & \% \\
\hline Theft & 40 & 18.2 \\
\hline Fraud & 25 & 11.4 \\
\hline Human Error & 50 & 22.7 \\
\hline Lack of employees & 105 & 47.7 \\
\hline
\end{tabular}

Table 8 shows that the majority of the respondents $(47.7 \%)$ faced the issue of lack of employees where separation of duties was difficult, followed by Human Errors as a recurring issue with $22.7 \%$. Only $11.4 \%$ of the respondents reported that they had the issues of fraud as fraud is a very rare phenomenon to happen within SMEs due to fewer employees and small businesses.

Table 9 Owners Meeting the employees

\begin{tabular}{|l|c|c|}
\hline Periodicity & Frequency & $\boldsymbol{\%}$ \\
\hline Daily & 100 & 45.5 \\
\hline Weekly & 100 & 45.5 \\
\hline Monthly & 20 & 9.0 \\
\hline Quarterly & 0 & 0 \\
\hline Yearly & 0 & 0 \\
\hline
\end{tabular}


Table 9 shows that the majority of the respondents $(45.5 \%)$ reported that the owners of SMEs meet their employees either every week or daily. This confirmed that the employees meet their owners frequently. Only $9 \%$ of the respondents reported that they meet their owners every month. This might be because some of the owners were working away from Muscat. This is similar to the finding by Loan (2011) that the owners of SMEs meet their employees frequently to improve their operation, ensuring no errors.

\section{Table 10 Mode of Assets Protection}

\begin{tabular}{|l|c|c|}
\hline \multicolumn{1}{|c|}{ Protection through } & Frequency & \% \\
\hline Restricting access to the assets & 76 & 34.5 \\
\hline Use of device to enhance security & 18 & 8.2 \\
\hline Checking inventory periodically & 76 & 34.5 \\
\hline Preserving documents and record in safe & 50 & 22.8 \\
\hline
\end{tabular}

There were several methods for SMEs to protect their assets. Table 10 shows that the majority of the respondents $(34.5 \%)$ confirmed that either restricting access to the assets or checking inventory periodically was the preferred mode of assets protection in SMEs. $22.8 \%$ of the respondents confirmed that preserving documents and records in a safe was their preferred mode of assets protection. Only $8.2 \%$ of them reported that they used devices to enhance security because of the cost of buying several security devices. This is similar to the findings by Frazer (2016) that the security devices are meant to protect the companies from fraud and need to be installed in all the computers of the company restricting unauthorized persons from accessing the assets.

\section{Discussion/Conclusion}

From the above findings, it is observed that SMEs were using computers to perform their daily transactions. The accounting software used by SMEs was cheap, of low quality, and not proficient enough. There was no SME that seemed to use manual receipts as manual preparation caused errors often and it was stated that with the use of computerized accounting systems, internal control systems were taken into consideration avoiding error, theft, and fraud in the company.

It was noticed that owners of SMEs frequently check on their employees and the sales received. One of the components of an internal control system, i.e. monitoring was implemented by most of the SMEs. But most of the SMEs stated that they rarely hired an external auditor for auditing their company because of the expensive auditing fees. The employees were aware of the importance of the internal control system as work became easier and evading errors.

It was also stated that the security mechanisms were not properly implemented in the SMEs because of the expensive cost. Adding security features to the computers were not set up because of expensive cost. The mechanism of safeguarding the assets of the company was reported implemented by the companies. The computers were allowed access only to the authorized personnel.

\section{Suggestions}

From the results of the study, the recommendations made to face the challenges were as follows:

- To have an effective and efficient operation, internal control should be implemented by the SMEs to avoid problems. The Government should emphasize the SMEs implement a good internal control system for their sake.

- The companies should increase the number of employees to avoid work overloading with few employees. This can reduce errors and increase the efficiency of operations.

- The accounting system should be installed with a sufficient security mechanism that can protect the documents and information and prevent fraud.

- The Government should amend and implement SOX in Oman to Omani context as SOX - the set of rules and regulations which are implemented for good governance, deals mainly with access, security, and data backups and helps to prevent data breaches within the company. 
- SOX in the Omani context should be strictly implemented making it statutory and mandatory for all the SMEs in Oman. Such statutory laws will help the auditors to abide by the rules and regulations to be followed.

- Government should support SMEs by providing education on the importance of internal control systems as most of the employees of SMEs are poorly educated/illiterates.

- The Government should set a price ceiling to the external auditors on the auditing fees exclusively for SMEs so that they can afford them.

\section{References}

1. Abdulle, A. S. S., Zainol, Z. \& Ahmad, H. (2019). Impact of Computerised Accounting Information System on Small and Medium Enterprises in Mogadishu, Somalia: The Balanced Scorecard Perspectives. International Journal of Engineering and Advanced Technology, 8(5C), 159-165. http://doi.org/10.35940/ijeat.E1023.0585C19

2. Adesoji, A.O. (2004). Internal Control System in a Computerized Accounting Environment. Dissertation Submitted to the Federal University of Technology, Nigeria.

3. Adewale, O. H. (2014). Internal control system: a managerial tool for proper accountability a case study of Nigeria customs service. European Scientific Journal, 10(13), 252-267.

4. Akhmetshin, E.M., Vasilev, V.L., Mironov, D.S., Zatsarinnaya, E.I., Romanova, M.V. \& Yumashev, A.V. (2018). Internal Control System in Enterprise Management: Analysis and Interaction Matrices. $\begin{array}{lllll}\text { European } & \text { Research } & \text { Studies } & \text { 728-740. }\end{array}$ https://www.um.edu.mt/library/oar//handle/123456789/33811

5. Alqassabi, M. A., (2020). Insights on Sustainability of Small and Medium Enterprises in Oman: A Conceptual Framework. International Journal of Economics and Financial Issues, 10(1), 209-218. https://doi.org/10.32479/ijefi.9063

6. Alawaqleh, Q. A. (2021). The Effect of Internal Control on Employee Performance of Small and Medium-Sized Enterprises in Jordan: The Role of Accounting Information System. Journal of Asian Finance, Economics and Business, 8(3), 855-863. http://doi.org/10.13106/jafeb.2021.vol8.no3.0855

7. Buabeng, A.A. (2020). A Comparative Case Study of Internal Controls and the Impact of Fraud on Nonprofit Organizations, Doctoral dissertation submitted to Northcentral University. https://www.proquest.com/docview/2451380720?pq-origsite=gscholar\&fromopenview=true

8. Curtis (2015, $11^{\text {th }}$ Jun. 2015). Omanization Compliance for Small and Medium Enterprises. Oman Law Blog, https://omanlawblog.curtis.com/2015/06/omanisation-compliance-for-small-and.html

9. Curtis, M. B. \& Wu, F. H. (2000). The Components of a Comprehensive Framework of Internal Control. The CPA Journal, 70(3), 64-66.

10. Dionne, G. (2013). Risk management: History, Definition, and Critique. Risk Management and Insurance Review, 16(2), 147-166. http://doi.org/10.1111/rmir.12016

11. Dawson, S. (2015). Internal Control/Anti-Fraud Program Design for the Small Business: A Guide for Companies NOT Subject to the Sarbanes-Oxley Act. John Wiley \& Sons.

12. Elahi, E. (2013). Risk Management: The Next Source of Competitive Advantage. Foresight, 15(2), 117131. http://doi.org/10.1108/14636681311321121

13. Fourie, H. \& Ackermann, C. (2013). The Impact of COSO Control Components on Internal Control Effectiveness: An Internal Audit Perspective. Journal of Economic and Financial Sciences, 6(2), 495518. https://hdl.handle.net/10520/EJC142871

14. Frazer, L. (2016). Internal Control: Is it a Benefit or Fad to Small Companies? A Literature Dependency Perspective. Journal of Accounting \& Finance, 16(4), 149-161. http://t.www.nabusinesspress.com/JAF/FrazerL_Web16_4_.pdf

15. Gebramicheal, Z.B. \& Habtegiorgis, T.T. (2019). Internal Control in Swedish Small and Medium Size Enterprises. MBA Dissertation submitted to IMEA School of Business, Sweden, 1-67. https://www.divaportal.org/smash/record.jsf?pid=diva2\%3A328364\&dswid=8196

16. Geiger, M. A., Cooper, S. M. \& Boyle, E. J. (2004). Internal Control Components: Did COSO Get It Right? CPA Journal, $28-31$. https://scholarship.richmond.edu/cgi/viewcontent.cgi?referer=https://scholar.google.com/\&httpsredir= $\underline{1 \& \text { article }=1001 \& \text { context }=\text { accounting-faculty-publications }}$ 
17. Greene, J. J. (2017, $3^{\text {rd }}$ May 2017). Considering Oman's Code of Corporate Governance. Gowling WLG. https://www.alalawico.com/documents/Corporate\%20\%20Governance\%20\%20(3\%20May\%202017). $\underline{\mathrm{pdf}}$

18. Hanini, E. (2015). Evaluating the Reliability of the Internal Control on the Computerized Accounting Information Systems: An Empirical Study on Banks Operating in Jordan. Research Journal of Finance and

Accounting,

$6(8)$

176-187. https://www.researchgate.net/publication/328202657_Evaluating_the_Reliability_of_the_Internal_Con trol_on_the_Computerized_Accounting_Information_Systems_An_Empirical_Study_on_Banks_Oper ating_in_Jordan

19. Kazaz, A., Erkovan, E. \& Ulubeyli, S. (2019). An Example of Internal Control Application for Contractor Companies in the Construction Sector. Proceedings of the $5^{\text {th }}$ International Conference on Engineering and Natural Science, 497-505.

20. Khan, F. R. (2008). Internal Control over Financial Reporting and Corporate Governance: An empirical study on practices and standards in Oman. Journal for Global Business Advancement, 5(1), 205-220.

21. Kowalczyk, D. (2019, 30 ${ }^{\text {th }}$ Aug. 2019). Descriptive Research: Definition, Examples \& Types. Study.com,

https://study.com/academy/lesson/descriptive-research-design-definition-examplestypes.html

22. Loan, T. (2011). Internal Control System for Small Business to Reduce Risk of Fraud, Case study: Company D, Vietnam. Degree thesis submitted to Arcada University of Applied Sciences, Vietnam. https://www.theseus.fi/bitstream/handle/10024/96198/Internal\%20control\%20system\%20for\%20small $\%$ 20business \%20to\%20reduce\%20risk\%20of\%20fraud Tran\%20Loan.pdf; sequence $=1$

23. Lunenburg, F. C. (2010). Communication: The process, Barriers, and Improving Effectiveness. Schooling, 1(1), 1-10.

24. Lutui, R. \& 'Ahokovi, T. (2018). The Relevance of a Good Internal Control System in a Computerised Accounting Information System. In Proceedings of the 16th Australian Information Security Management Conference (pp. 29-40). Perth, Australia: Edith Cowan University. http://doi.org/10.25958/5c5270a16668d

25. Mahadeen, B., Al-Dmour, R. H., Obeidat, B. Y. \& Tarhini, A. (2016). Examining the effect of the Organization's Internal Control System on Organizational Effectiveness: A Jordanian empirical study. International Journal of Business Administration, 7(6), 22-41. http://doi.org/10.5430/ijba.v7n6p22

26. Mardi, M., Perdana, P. N., Suparno, S., \& Munandar, I. A. (2020). Effect of Accounting Information Systems, Teamwork, and Internal Control on Financial Reporting Timeliness. The Journal of Asian Finance, Economics and Business, 7 (12), 809-818. https://doi.org/10.13106/jafeb.2020.vol7.no12.809

27. McCombes, S. (2020, $3^{\text {rd }}$ Sep. 2020). Descriptive Research. Methodology, Scribbr., https://www.scribbr.com/methodology/descriptive-research/

28. Owusu-Ansah, E. (2019). Study on the Effectiveness of Internal Control Systems in Ghana Public Sector: A Look into The District Assemblies. Part 1. Bulletin of the Peoples' Friendship University of Russia. Series: State and Municipal Administration, 6(3), 193-212. http://doi.org/10.22363/2312-83132019-6-3-193-212

29. Putra, Y. H. S. (2014). Detecting Internal Control Problems Based on COSO and Islamic Perspective: Case on SMEs.Tazkia Islamic Finance and Business Review, 8(1), 25-44. http://dx.doi.org/10.30993/tifbr.v8i1.60

30. Sera, Y. \& Beaudry, S. (2007). Monitoring \& Evaluation: Tips for Strengthening Organizational Capacity. World Bank Small Grants Programme Briefing Note: World Bank 2007.Washington, DC: The Social Development Department of the World Bank Group, 952489-1228423929687.

31. Shanmugam, J. K., Ali, A., \& Haat, M. H. C. (2012). Internal Control, Risk Management and Fraud Prevention Measures on SMEs: Reliability and Validity of Research Instrument. Proceedings of the $3^{\text {rd }}$ International Conference on Business and Economic Research, Small, 100, 12-18.

32. Soudani, S. N. (2013). The Implementation of E-Accounting Systems on Financial Performance with Effects of Internal Control Systems, Research Journal of Finance and Accounting, 4(11), 17-27. https://www.researchgate.net/publication/314281291_The_Implementation_of_E-

Accounting_Systems_on_Financial_Performance_with_Effects_of_Internal_Control_Systems

33. Steinberg, R. M. (2011, 20 ${ }^{\text {th }}$ Dec. 2011). Revised COSO Internal Control Framework Is Here. Compliance Week, 9(96), 40-41. https://www.complianceweek.com/revised-coso-internalcontrol-framework-is-here/17028.article

34. Wei, W. (2015). Internal Accounting Control Based on Computerization System, Metallurgical \& Mining Industry, 7, 151-158. https://search.ebscohost.com/login.aspx?direct=true\&site=edslive \&db=asn\&AN=115932610 
35. Yan-ling, H. (2017). Analysis on the Internal Control of Enterprise Accounting under Computer Network Environment, 2017 IEEE International Conference on Computational Science and Engineering (CSE) and IEEE International Conference on Embedded and Ubiquitous Computing (EUC), 1, 712-715. http://doi.org/10.1109/CSE-EUC.2017.138

36. Zhang, Y. (2021). On the Application of Computer in the Internal Control of Financial Accounting System. Journal of Physics: Conference Series, (MACE 2020), 1744 0402066, 1-5. http://doi.org/10.1088/1742-6596/1744/4/042066 